\title{
Study of the Blending Efficiency of Pitched Blade Impellers
}

\author{
I. Fořt, T. Jirout, F. Rieger, R. Allner, R. Sperling
}

This paper presents an analysis of the blending efficiency of pitched blade impellers under a turbulent regime of flow of an agitated low viscous liquid. The conductivity method is used to determine of the blending (homogenization) time of miscible liquids in pilot plant mixing equipment with standard radial baffles. For the given homogeneity degree (98\%) a three-blade pitched blade impeller is tested with various off- bottom clearances, vessel/ impeller diameter ratios and various impeller pitch angles.

The experimental results show in accordance with theoretical data from the literature, that the greatest effect on the dimensionless blending time is exhibited by the vessel/ impeller diameter ratio and the impeller pitch angle. The number of total circulations necessary for reaching the chosen homogeneity degree depends on the impeller pitch angle and amounts more than three. Finally, the energetic efficiency of the blending process is calculated.The results of this study show, that the highest energetic efficiency of the three-blade pitched blade impeller appears for the pitch angle $\alpha=24^{\circ}$, the impeller/vessel diameter ratio $T / D=2$ and the impeller off-bottom clearance $h / D=1$.

Keywords: pitched blade impeller, blending of liquids, degree of homogeneity, turbulent flow.

\section{Introduction}

Stirring processes are used in many parts of the chemical, pharmaceutical, food and bioengineering industries. In most of them the stirring is a basic operation, e.g. during homogenization (or blending) of miscible liquids, i.e. the compensation of temperature and concentration differences. For such a process it is very important to know the blending efficiency when designing an industrial plant. However, the optimal design of stirring plants also involves better economics of the mixing process. In this paper we study the problems of the blending efficiency of pitch blade impellers $(P B I)$, especially the course of homogenization performed by a three blade $(3-b) P B I$ with various pitch angles and different vessel/impeller diameter ratios. There are a few papers dealing with experimentally determined results of blending times of the $P B I$ [e.g. 1, 2, 3, 4] but no study describing the blending efficiency of the above mentioned impellers has yet appeared up to now. Therefore, additional experimental data needs to be compiled to supplement our knowledge of the blending efficiency of the 3-b PBI, with different geometric configurations.

\section{Theoretical}

Let us consider a three-blade pitched blade impeller (3-b PBI) in a blending process of low viscous miscible liquids. We can assume the turbulent regime of flow of the agitated batch. The dependence of the dimensionless time of homogenization (mixing time) on the Reynolds number (Re), modified for rotary impeller

$$
\operatorname{Re}=n D^{2} \rho / v,
$$

expressed by the function

$$
n t=n t(\operatorname{Re})
$$

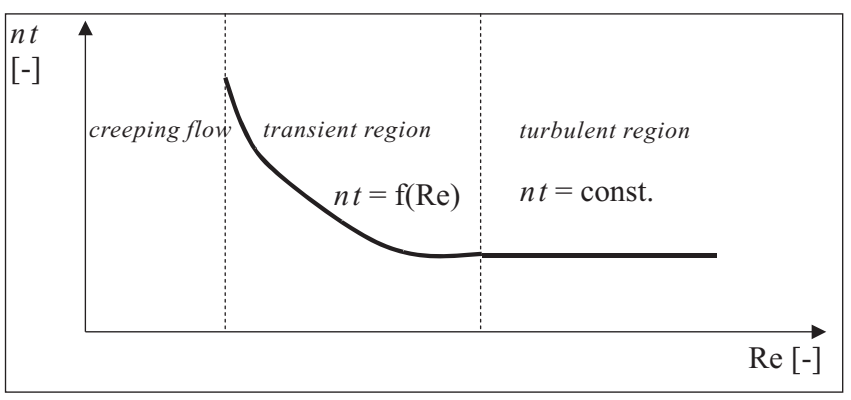

Fig. 1: Typical dependence of dimensionless blending time on the Reynolds number for a high-speed rotary impeller

can be distributed in three regions (see Fig. 1):

In the range $\operatorname{Re}<10$, the liquid around the impeller moves with the impeller rotation. Therefore, the process of mixing is negligible and the real mixing time is very long.

When the $\operatorname{Re}>10$, the flow around the impeller is turbulent. With an increase of the Reynolds number the viscous forces in the rest of the agitated batch decrease and the inertia forces increase.

In the range $\operatorname{Re}>10^{4}$, the negligible effects of the viscous forces and the forces in the whole agitated batch are only the inertial forces. The dimensionless blending time does not depend on the Reynolds number but it depends on the geometry of the agitated system and on the chosen degree of homogeneity [5]

$$
C(t)=\frac{[c(t)]-c_{\mathrm{k}}}{c_{0}-c_{\mathrm{k}}}
$$

where the average concentration in the volume of the mixed batch apart from the volume of the concentration impulse $\Delta V$

$$
c(t)=\frac{1}{V} \int c(v, t) \mathrm{d} V
$$


The initial concentration is defined as

$$
c_{0}=[c(t=0)]
$$

and the final concentration of the dissolved matter in the agitated liquid is

$$
c_{k}=[c(t \rightarrow \infty)] .
$$

Quantity $c(t)$ is the instantaneous concentration of the dissolved matter averaged over the volume of agitated liquid volume $V$, reduced about the volume of concentration impulse $\Delta V$. For the sake of simplicity we neglect the volume $\Delta V$ with respect to value $V$; the value $\Delta V$ amounts to less than one thousanth of value $V$.

Turbulent flow of an agitated liquid is realized by its circulation. For the given homogeneity degree the blending process takes place during the given number of the total liquid circulation $n_{\mathrm{C}}[5]$

$$
t=n_{\mathrm{C}} t_{\mathrm{T}}, \quad[C=\text { const. }]
$$

where $t_{\mathrm{T}}$ is the mean time of total liquid circulation, which can be calculated from the relation

$$
t_{\mathrm{T}}=\frac{V}{Q_{\mathrm{T}}}
$$

where $Q_{\mathrm{T}}$ is the total volumetric flow of the agitated liquid. If we consider a "squared" configuration of the volume of the agitated liquid, i.e.

$$
V=\frac{\pi}{4} T^{3}
$$

and introduce the total flowrate number

$$
N_{Q_{\mathrm{T}}}=\frac{Q_{\mathrm{T}}}{n D^{3}}
$$

we can finally rearrange Eq. (2) into the form

$$
n t=n_{\mathrm{C}} \frac{\pi}{4}\left(\frac{T}{D}\right)^{3} \frac{1}{N_{Q_{\mathrm{T}}}}, \quad[\mathrm{C}=\text { const. }]
$$

Eq. (11) includes impeller speed $n$, impeller diameter $D$, and the mixing vessel diameter $T$.

The energetic blending criterion $E$ indicates the energy consumption ratio necessary for the chosen homogeneity degree [6]:

$$
E=\frac{P t^{3}}{\rho T^{5}}=P_{0}(n t)^{3}\left(\frac{D}{T}\right)^{5} .
$$

To calculate the energetic criterion we need to know the impeller power input $P$ and the mixing time for the given configuration of the agitated system. Quantity $P$ can be calculated from the power number

$$
P_{0}=P / \rho n^{3} D^{5}
$$

where $\rho$ is the density of the agitated liquid. The quantity $P_{0}$ depends on the geometry of the system agitated by a $P B I$ and this dependence can be expressed by the equation [7]

$$
P_{0}=1.507(T / D)^{-0.365}(h / D)^{-0.165}(H / T)^{0.140} n_{\mathrm{B}}^{0.171}(\sin \alpha)^{2.077},(14)
$$

valid for values of the Reynolds number greater than $10^{4}$. It consists among others of quantities $n_{\mathrm{B}}$ - the number of impeller blades, $\alpha$ - the pitch angle of the impeller blades, and $h$ - the impeller off-bottom clearance.

\section{Experimental}

After the injection of a small amount of tracer $\Delta V$ (about $1 \mathrm{ccm}$ ) into the agitated liquid, the concentration changes and mixing time were measured in appropriate locations in the agitated liquid. The conductivity method was used for measuring the blending time. This method is based on the principle of monitoring the changes in electrical conductivity within the mixed liquid. The change in electrical conductivity was caused by adding a sample of concentrated solution of sodium chloride into the liquid below its surface along the impeller shaft. In our experiments the injected sample of liquid had approximately the same density and viscosity as the mixed liquid, and thus the effect of the Archimedes number was eliminated. After adding the tracer the time change of conductivity was measured and recorded and the blending time was determined. The conductivity cell consisted of two platinum wire electrodes of $0.8 \mathrm{~mm}$ diameter in the shape of a rectangle $8 \times 10 \mathrm{~mm}, 8 \mathrm{~mm}$ apart. The volume of the conductivity cell was approximately $0.8 \mathrm{ccm}$. The cell was located at of the liquid height under the surface of the mixed liquid and at $1 / 10$ of the vessel diameter from the wall of the vessel (see Fig. 2). We chose this position because

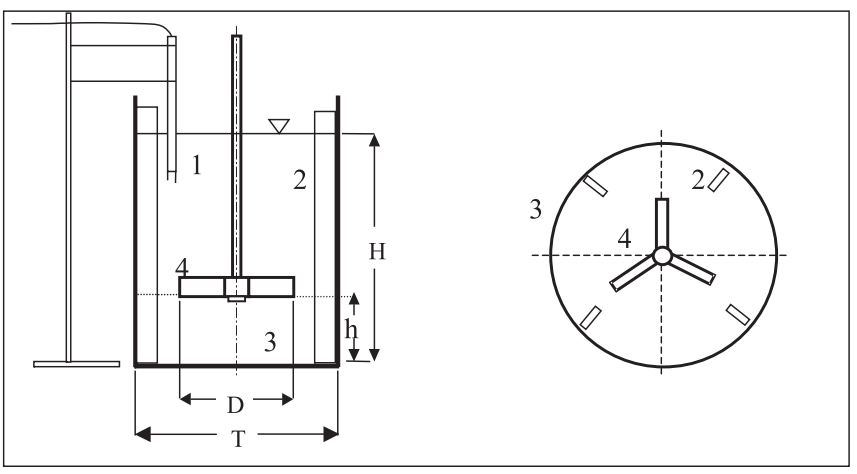

Fig. 2: Cylindrical vessel with a high-speed rotary impeller, radial baffles and position of the conductivity probe; (1-conductivity probe, 2- baffle, 3-vessel, 4- impeller)

during a test with the decolourizing method a dead space was detected in this volume for the impellers and vessels under investigation. The volume of the liquid injected varied in the range $0.5-1.5 \mathrm{ccm}$. The process of homogenization was recorded with a fast chart recorder. The time of homogenization (the blending time) was found at the moment when the fluctuation of the measured electrical voltage $U$ was $\pm 2 \%$. A typical time course of the indicated voltage is shown in Fig. 3.

The principle layout of the pilot plant experimental equipment is shown in Fig. 2. The blending time was determined at various geometric configurations; in all of the cases the impeller was pumping liquid downwards - towards the bottom of the cylindrical vessel and was located in its axis of symmetry.

Measurements were carried out with two different series of 3-b PBIs (Fig. 4 shows the geometry of the impellers used) with diameters of $100 \mathrm{~mm}$ and $67 \mathrm{~mm}$, respectively. For each impeller we used three different pitch angles:

$$
\alpha=24^{\circ}, 35^{\circ} \text {, and } 45^{\circ} \text {. }
$$




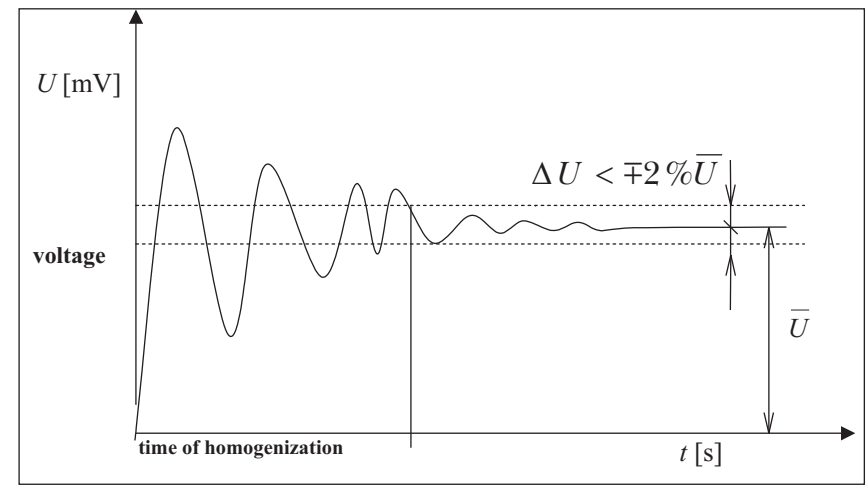

Fig. 3: Recorded trace (example of the time course of homogenization)

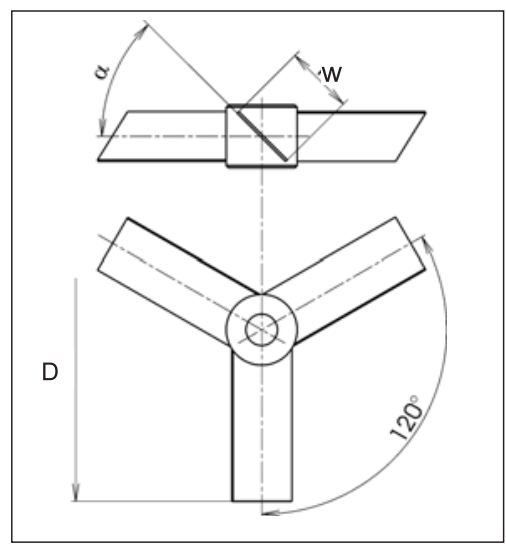

Fig. 4: Three-blade pitched blade impeller $(D=67 \mathrm{~mm}, 100 \mathrm{~mm}$, $h / D=0.2)$

For all the impellers the three different vessel/impeller ratios were investigated: $T / D=2,3,4.5$. The influence of the impeller off-bottom clearance was studied at the standard configuration $\left(T / D=3, \alpha=45^{\circ}\right)$. All these configurations are summarized in Tab. 1. Additionally, the blending time was determined with a dish shaped bottom of the vessel (for $T / D=2,3$ and $\alpha=45^{\circ}$ ). All the vessels were equipped with four baffles distributed equally around the vessel wall (see Fig. 2). The ratio between baffle width $b$ and the vessel diameter $b / T=0.1$.

A larger interval of the Reynolds number was covered by using three different levels of viscosities of the tested liquids:
1. Distilled water [viscosity around $1 \mathrm{mPa} \cdot \mathrm{s}$ ], 2. $25 \% \mathrm{w} / \mathrm{w}$ glycerol water solution [viscosity around $2 \mathrm{mPa} \cdot \mathrm{s}$ ], and $3.45 \% \mathrm{w} / \mathrm{w}$ glycerol water solution [viscosity around $4 \mathrm{mPa} \cdot \mathrm{s}$ ]. The viscosity was measured with the Hoeppler Viscosimeter B3 (MLW Prufgeraetewerke, Freital, Germany) at five different temperatures, and the viscosity of the mixed liquid was calculated by linear interpolation from its known temperature dependence.

The accuracy of the data obtained depends significantly on the independent variables, i.e. the viscosity of the mixed liquid, the impeller speed and on the geometric configuration of the agitated system. The impeller speed was measured by a photoelectric revolution counter having an accuracy of $\pm 1 / \mathrm{min}$. The diameter of the impeller and the width of its blade were manufactured with an accuracy of $\pm 0.1 \mathrm{~mm}$ and the pitch angle within an accuracy of \pm 30 '. The impeller position in the vessel and the height of liquid in the vessel were measued by a ruler with an accurancy of $\pm 1 \mathrm{~mm}$. The accuracy of measurement of the dynamic viscosity was $\pm 0.1 \mathrm{mPa} \cdot \mathrm{s}$.

The process of homogenization was recorded with a fast chart recorder with a scale $1 \mathrm{~mm} \sim 1$ second. The accuracy of determination of the blending time was considered $\pm 1 \mathrm{~s}$. For each configuration of the agitated system the blending time was measured at five different values of impeller speed at constant viscosity of the mixed liquid. Because of the required confidence level of the final experimental results $[3,4,6]$, the five courses of blending time for each impeller speed were determined and the average value for the given experiment was calculated. The blending time measured and calculated by this process exhibits a relative deviation of $\pm 5 \%$ from the calculated average value.

\section{Results and discussion}

The results of the experiments were evaluated from the point of view of dependence of the blending time on the geometric parameters of the agitated system and, further, according to the formulas in the theoretical part of this study, evaluations were made to investigate the relation between the blending time and the mixed liquid circulation. Finally, the blending efficiency of the 3-b PBI was calculated with respect to various geometries of the investigated system with the aim to find the optimal arrangement for the blending process. It follows from all the results of the experiments (see examples in Fig. 5, 6) that when the Reynolds number (modified for a rotary impeller) exceeds ten thousand the dimensionless blending time does not depend on Re.

Table 1: Pilot plant configurations for investigation for $n_{\mathrm{B}}=3 ;(H=T)$

\begin{tabular}{|c|c|c|c|c|c|c|c|c|}
\hline $\begin{array}{c}\text { Vessel/Impeller } \\
\text { diameter ratio } \\
\boldsymbol{T} / \boldsymbol{D}[-]\end{array}$ & $\begin{array}{r}\text { Impel } \\
\text { cleara } \\
\text { dia }\end{array}$ & $\begin{array}{l}\text { pottom } \\
\text { peller } \\
\text { atio }\end{array}$ & $\begin{array}{c}\text { Diameter of Vessel } \\
T[\mathrm{~mm}]\end{array}$ & $\begin{array}{l}\text { Diameter of Impeller } \\
\qquad \boldsymbol{D}[\mathrm{mm}]\end{array}$ & \multicolumn{4}{|c|}{$\begin{array}{l}\text { Off-bottom Clearance } \\
\qquad \boldsymbol{h}[\mathrm{mm}]\end{array}$} \\
\hline 2 & \multicolumn{2}{|c|}{1} & 200 & 100 & \multicolumn{4}{|c|}{100} \\
\hline 3 & $\begin{array}{l}1 \\
0.50\end{array}$ & $\begin{array}{l}0.75 \\
0.333\end{array}$ & $\begin{array}{l}200 \\
300 \\
\end{array}$ & $\begin{array}{c}67 \\
100 \\
\end{array}$ & $\begin{array}{l}67 \\
100\end{array}$ & $\begin{array}{l}50 \\
75\end{array}$ & $\begin{array}{l}33 \\
50\end{array}$ & $\begin{array}{l}22 ; \\
33 ;\end{array}$ \\
\hline 4.5 & \multicolumn{2}{|c|}{1} & 300 & 67 & \multicolumn{4}{|c|}{100} \\
\hline
\end{tabular}




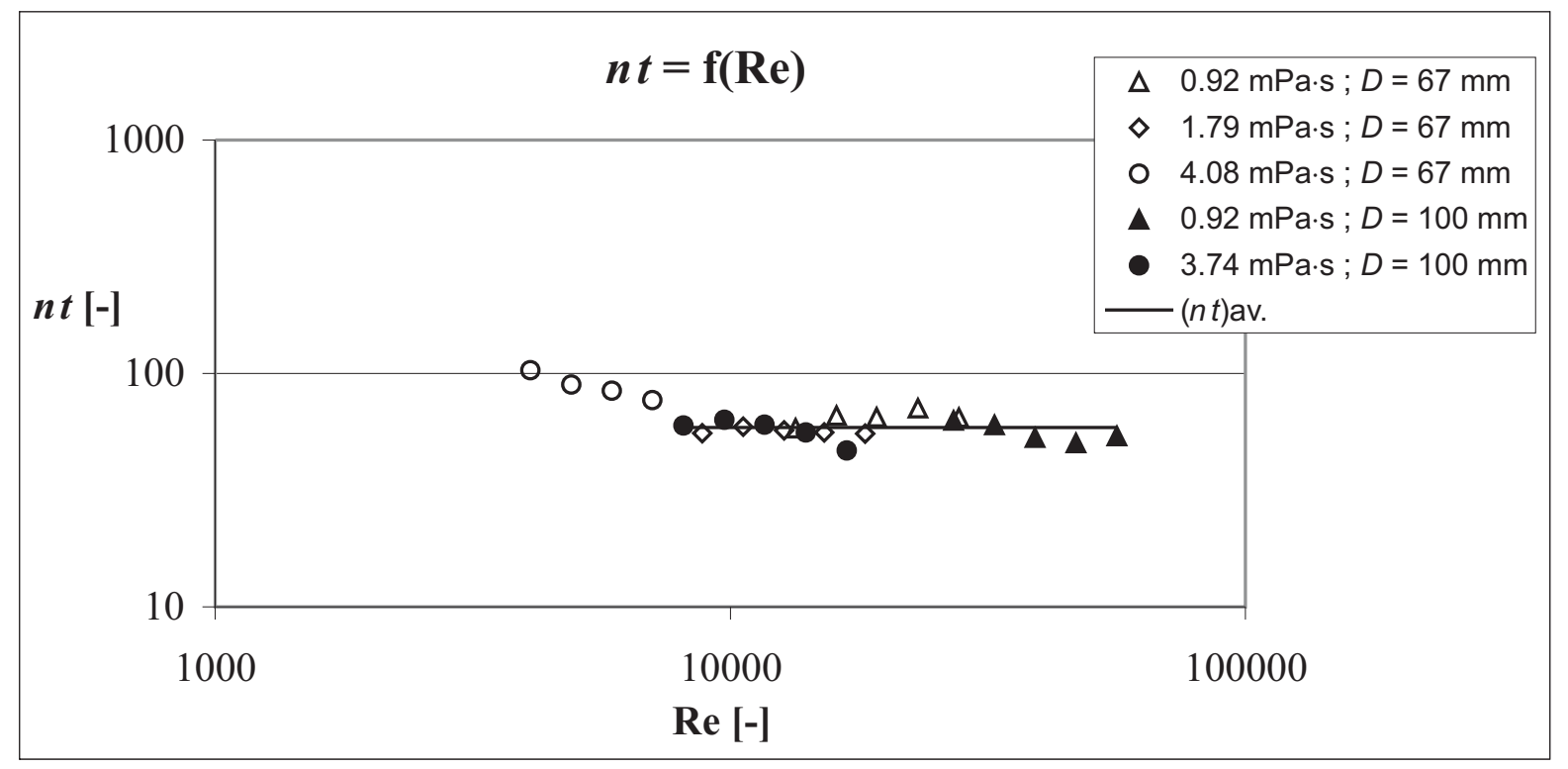

Fig. 5: Dimensionless blending time as a function of $\operatorname{Re},\left(D=67,100 \mathrm{~mm}, T / D=3, \alpha=35^{\circ}\right)$ for different viscosities of mixed liquid

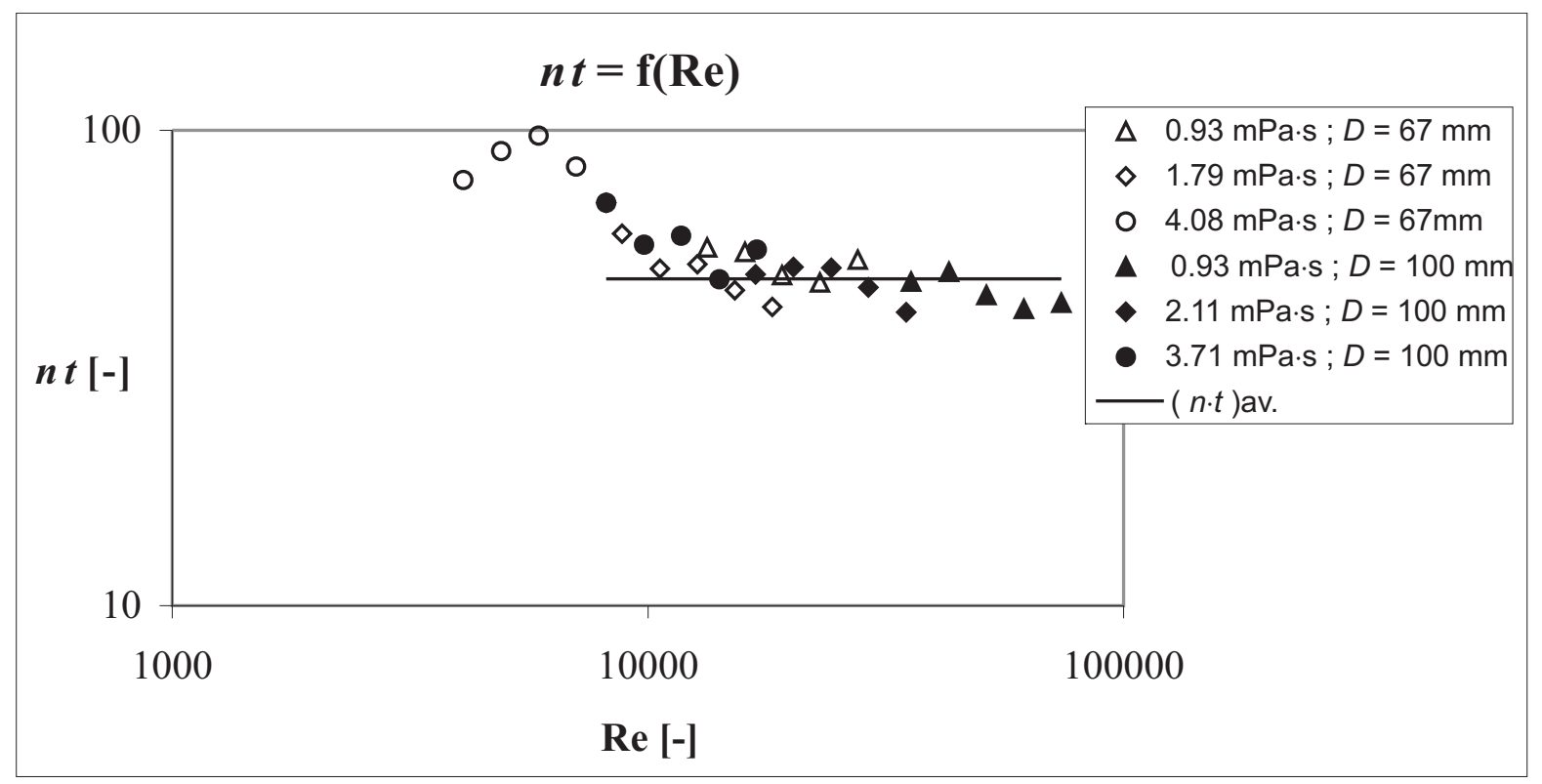

Fig. 6: Dimensionless blending time as a function of Re, $\left(D=67,100 \mathrm{~mm}, T / D=3, \alpha=\mathbf{4 5}^{\circ}\right)$ for different viscosities of mixed liquid

\section{Dependence of the blending time on the geometry of a mixed system}

Taking into account the independence of the quantity $n t$ from the Reynolds number for the turbulent regime of flow of an agitated liquid, the dependence of the dimensionless blending time on the geometric parameters of the mixing system was expected in the power form

$$
n t=K_{1}\left(\frac{T}{D}\right)^{a_{1}}\left(\frac{h}{D}\right)^{b_{1}}(\sin \alpha)^{c_{1}}
$$

or

$$
n t=K_{2}\left(\frac{T}{D}\right)^{a_{2}}\left(\frac{h}{D}\right)^{b_{2}} \alpha^{c_{2}}
$$

The values of the exponents $a_{\mathrm{i}}, b_{\mathrm{i}}, c_{\mathrm{i}}$ and the parameter $n_{\mathrm{i}}$, $(i=1,2)$ were calculated from the results of the experiments (see Tab. 2) by means of multidimensional log-log linear regression and they are listed in Tab. 3 together with the correlation coefficients $R_{\mathrm{i}},(i=1,2)$ of the corresponding regression equations. It follows from these two tables that there is no difference between the agreements of the two proposed equations $\left[(n t)_{\text {calc }}\right.$ vers. $\left.(n t)_{\exp }\right]$ and that the correlation coefficients of both equations are practically the same, expressing a suitable confidence level of the considered power dependence. When we look at the values of the exponents in Eqs. (15) and (16) the highest influence on the blending time is for the vessel/impeller diameter ratio: here the values of exponents $a_{1}$ and $a_{2}$ are approx. two. Similar values were found for the standard Rushton turbine impeller [3] and for four-blade [3] and 
Table 2: Dependance of dimensionless blending time on impeller pitch angle (three-blade pitched blade impeller), $C=0.02 ; n_{\mathrm{B}}=3$

\begin{tabular}{|c|c|c|c|c|c|}
\hline $\boldsymbol{D} / \boldsymbol{T}[-]$ & $\boldsymbol{h} / \boldsymbol{D}[-]$ & $\left.\alpha{ }^{\circ}\right](\mathrm{deg})$ & $(\boldsymbol{n t})_{\exp }[-]$ & $\begin{array}{c}(\boldsymbol{n t})_{\text {calc }}[-] \\
(\text { Eq. 15) }\end{array}$ & $\begin{array}{c}(\boldsymbol{n t})_{\text {calc }}[-] \\
(\mathrm{Eq} . \mathbf{1 6})\end{array}$ \\
\hline 2 & 1 & 24 & $32.8 \pm 2.0$ & 29.8 & 29.8 \\
\hline 2 & 1 & 35 & $25.3 \pm 1.3$ & 24.5 & 24.6 \\
\hline 2 & 1 & 45 & $18.6 \pm 1.0$ & 21.7 & 21.7 \\
\hline 3 & 1 & 24 & $60.3 \pm 4.2$ & 66.9 & 66.8 \\
\hline 3 & 1 & 35 & $58.3 \pm 2.7$ & 55.0 & 55.3 \\
\hline 3 & 1 & 45 & $49.2 \pm 2.2$ & 48.9 & 48.8 \\
\hline 4.5 & 1 & 24 & $142.0 \pm 8.1$ & 150.1 & 150.0 \\
\hline 4.5 & 1 & 35 & $118.0 \pm 11.2$ & 123.6 & 124.2 \\
\hline 4.5 & 1 & 45 & $112.0 \pm 10.5$ & 109.8 & 109.5 \\
\hline 3 & 0.33 & 45 & $54.5 \pm 3.2$ & 56.1 & 56.1 \\
\hline 3 & 0.50 & 45 & $55.3 \pm 4.8$ & 53.3 & 53.3 \\
\hline 3 & 0.77 & 45 & $51.8 \pm 3.5$ & 50.7 & 50.6 \\
\hline
\end{tabular}

Table 3: Parameters of the power regression for $\sin \alpha$ (Eq. 15) and $\alpha$ (Eq. 16), $C=0.02, n_{\mathrm{B}}=3, \operatorname{Re}>10^{4}$

\begin{tabular}{|c|c|c|c|c|c|}
\hline Eq. & $K_{\mathrm{i}}$ & $a_{\mathrm{i}}$ & $b_{\mathrm{i}}$ & $c_{\mathrm{i}}$ & $R_{\mathrm{i}}$ \\
\hline $\mathbf{1 5}, i=1$ & 4.49 & 1.994 & -0.125 & -0.566 & 0.992 \\
\hline $\mathbf{1 6}, i=2$ & 36.63 & 1.994 & -0.128 & -0.501 & 0.992 \\
\hline
\end{tabular}

Table 4: Number of total liquid circulations for the given homogeneity degree $(C=0.02)$ and the number of impeller blades $\left(n_{\mathrm{B}}=3\right)$

\begin{tabular}{|c|c|c|c|c|c|c|}
\hline$\alpha\left[^{\circ}\right](\mathrm{deg})$ & $D / T[-]$ & $\boldsymbol{h} / \boldsymbol{D}[-]$ & $n t$ & $N_{\mathrm{QT}}[-]$ & $n_{\mathrm{C}}[-]$ & $\boldsymbol{n}_{\mathrm{C}, \text { av }}[-]$ \\
\hline 45 & 3 & 0.30 & 54.1 & 1.614 & 4.116 & \multirow{4}{*}{4.072} \\
\hline 45 & 3 & 0.50 & 55.3 & 1.654 & 4.313 & \\
\hline 45 & 3 & 0.75 & 51.8 & 1.706 & 4.167 & \\
\hline 45 & 3 & 1.00 & 47.3 & 1.654 & 3.961 & \\
\hline 24 & 2 & 1.00 & 37.8 & 0.686 & 3.584 & \multirow{3}{*}{3.323} \\
\hline 24 & 3 & 1.00 & 60.3 & 1.024 & 2.913 & \\
\hline 24 & 4.5 & 1.00 & 142.0 & 1.751 & 3.474 & \\
\hline 24 & 3 & 0.75 & 60.3 & 1.331 & 3.788 & \multirow{3}{*}{4.162} \\
\hline 35 & 3 & 0.75 & 58.7 & 1.637 & 4.534 & \\
\hline 45 & 3 & 0.75 & 51.8 & 1.706 & 4.167 & \\
\hline
\end{tabular}

six blade PBIs [4]. The values of the exponents $c_{1}$ and $c_{2}$ are moderate and do not differ significantly. The higher the pitch angle, the lower the blending time.

Table 4 presents a survey of calculated values of the number of total liquid circulations nC necessary for attaining the given homogeneity degree. The values of the total flow rate number $N_{\mathrm{QT}}$ were taken from the literature [5] and the corresponding values of the dimensionless blending time $n t$ follow from this study. It follows from this table that $3-4$ circulations of the mixed liquid are necessary for attaining the degree of homogeneity required, and that the impeller off-bottom clearance does not exhibit a significant influence on this number. It seems that a decrease in the impeller blade pitch angle causes a decrease in the number of liquid circulations, but independently of the vessel/impeller diameter ratio.

\section{Energetic blending criterion}

Energetic blending criterion $E$ (see Eq. 12) characterizes in dimensionless form the energy necessary for attaining the chosen homogeneity of the agitated liquids. The higher the energetic blending criterion the lower the blending efficiency at the given geometry of agitated system. Table 5 gives a survey of the values of quantity $\mathrm{E}$ following from our experimental data on blending time. The impeller power number $P o$ was calculated from Eq. (14). 
Table 5: Dependence of the energetic blending criterion on the geometry of an agitated system with a three-blade pitched blade impeller $(C=0.02)$, flat bottom of cylindrical vessel

\begin{tabular}{|c|c|c|c|c|c|}
\hline$\left.\alpha{ }^{\circ}\right](\mathrm{deg})$ & $\boldsymbol{D} / \boldsymbol{T}[-]$ & $\boldsymbol{h} / \boldsymbol{D}[-]$ & $\boldsymbol{n t}[-]$ & $\boldsymbol{P o}[-]$ & $\boldsymbol{E}[-]$ \\
\hline 24 & 2 & 1 & 37.8 & 0.39 & 430 \\
\hline 24 & 3 & 1 & 60.3 & 0.34 & 367 \\
\hline 24 & 4.5 & 1 & 142.0 & 0.29 & 450 \\
\hline 35 & 2 & 1 & 25.3 & 0.80 & 403 \\
\hline 35 & 3 & 1 & 58.7 & 0.69 & 572 \\
\hline 35 & 4.5 & 1 & 118.0 & 0.59 & 528 \\
\hline 45 & 2 & 1 & 18.6 & 1.23 & 236 \\
\hline 45 & 2 & 1 & 18.3 & 1.23 & $247^{\mathrm{a})}$ \\
\hline 45 & 3 & 1 & 42.3 & 1.06 & $329^{\mathrm{a})}$ \\
\hline 45 & 3 & 1 & 48.7 & 1.06 & 454 \\
\hline 45 & 3 & 0.75 & 51.8 & 1.11 & 633 \\
\hline 45 & 3 & 0.50 & 55.3 & 1.19 & 824 \\
\hline 45 & 3 & 0.33 & 54.5 & 1.29 & 858 \\
\hline 45 & 4.5 & 1 & 112.0 & 0.92 & 697 \\
\hline
\end{tabular}

a) Dished bottom

For the pitch angle $\alpha=45^{\circ}$ we can see a permanent increase in the energetic blending criterion with the increasing ratio $T / D$. For the pitch angles $\alpha=24^{\circ}$ and $35^{\circ}$ a monotonous trend cannot be seen, e.g. the energetic criterion for $\alpha=35^{\circ}$ is similar for ratios $T / D=3$ and 4.5 , while at the ratios $T / D=2$ and 4.5 for pitch angle $\alpha=24^{\circ}$ the values of the energetic criterion have a difference of just $4 \%$. The difference between the criteria corresponding to the ratios $T / D=3$ and 4.5 is about $20 \%$.

The vessel/impeller ratio exhibits an influence on the difference between the values of the energetic blending criterion when the flat bottom of the vessel is replaced by a dished bottom. Here the difference is more significant for the ratio $T / D=3$, where the flow pattern of the agitated liquid follows better the shape of the bottom, and then the blending process is faster than in the system with the flat bottom.

The data in Tab. 5 show also that there is a dependence between the energetic blending criterion and the impeller off-bottom clearance. The energetic criterion $E$ decreases with increasing off-bottom clearance. The difference of the energetic criteria between the shortest and longest impeller off-bottom clearance is around $85 \%$. The favourable effect of decreasing the ratio $h / D$ can be explained by the fact that the liquid is pumped by the impeller towards the bottom, where the high level of turbulence contributes to the better blending process.

The energetic blending criterion $E$ increases with increasing pitch angle at the value of ratio $T / D=4.5$ but at the ratio $T / D=3$ we cannot find a clear trend for quantity $E$ as a function of quantity $\alpha$. Generally, for the off-bottom clearance $h / D=1$ criterion $E$ decreases with increasing pitch angle, but with certain exceptions especially around the pitch angle $\alpha=35^{\circ}$.

\section{Conclusions}

A three-blade pitched blade impeller seems to be suitable for blending processes under the turbulent regime of flow of an agitated liquid. The discovered correlation allows us to calculate the blending time for different pitch angles, ratios $D / T$ and $H_{2} / D$ at the homogeneity degree $C=0.02$. The most efficient energetic blending criterion among the geometries investigated seems to appear at the configuration $\alpha=24^{\circ}$, $T / D=2, h / D=1$ and, on the other hand, the most inefficient configuration was found at the geometry $\alpha=45^{\circ}, T / D=4.5$, $h / D=1$.

This research was subsidised by research project of the Ministry of Education of the Czech Republic No. J04/98: 212200008.

\section{List of Symbols}

$b$

C degree of homogeneity

c concentration, $\left[\mathrm{kg} \cdot \mathrm{m}^{-3}\right]$

$D \quad$ impeller diameter, $[\mathrm{m}]$

E energetic blending criterion

$H \quad$ total liquid depth, [m]

$h \quad$ impeller off-bottom clearance, [m]

$n$ impeller speed, [ $\left[\mathrm{sec}^{-1}\right.$ ]

$n_{\mathrm{B}} \quad$ number of impeller blades

nt dimensionless blending time

$N_{\mathrm{QT}}$ total flow rate number

$P \quad$ impeller power consumption, [W]

$P o \quad$ power number

$R \quad$ correlation coefficient 
Re Reynolds number modified for rotary impeller

$T$ vessel diameter, $[\mathrm{m}]$

$t \quad$ homogenization (blending) time, [sec]

$t_{\mathrm{T}} \quad$ time of total liquid circulation, [sec]

$Q_{\mathrm{T}} \quad$ total volumetric flow ratio of agitated liquid, $\left[\mathrm{m}^{3} \cdot \mathrm{s}^{-1}\right]$

$U$ voltage, [V]

$V \quad$ volume of agitated liquid, $\left[\mathrm{m}^{3}\right]$

$\Delta V \quad$ volume of concentration impulse, $\left[\mathrm{m}^{3}\right]$

$\alpha \quad$ pitch angle of impeller blades, ${ }^{\circ}(\mathrm{deg})$

$\eta \quad$ dynamic viscosity, $[\mathrm{Pa} \cdot \mathrm{s}]$

$\rho \quad$ density, $\left[\mathrm{kg} \cdot \mathrm{m}^{-3}\right]$

\section{Subscripts}

calc calculated value

exp experimental value

$\mathrm{k}$ final value

0 initial value

\section{References}

[1] Nagata, Sh.: Mixing. Principles and applications. Kodansha Ltd., Tokyo, John Wiley \& Sons, N. Y., 1975

[2] GVC-Fachauschuss "Mischvorgaenge": Mischen and Ruehren. VDI Gesellschaft Verfahrungstechnik und Chemieingenieurwesen, Dusseldorf, 1998

[3] Procházka, J., Landau, J.: Homogenization of Miscible Liquids by Rotary Impellers. Collect. Czech. Chem. Commun. 26, 1961, pp. 2961-2974

[4] Kvasnička, J.: Thesis. Research Institute of Chemical Equipment (VÚCHZ-CHEPOS), Brno, 1967
[5] Fořt, I., Valešová, H., Kudrna, V.: Liquid Circulation in a System with Axial Mixer and Radial Baffles. Collect. Czech. Chem. Commun. 36, 1971, pp. 164-185

[6] Rieger, F., Novák, V.: Homogenization Efficiency of Helical Ribbon and Anchor Agitators. Chem. Eng. Jour. 9, 1975, pp. 63-70

[7] Medek, J.: Power Characteristic of Agitators with Flat Inclined Blades. Int. Chem. Eng. 20, 1980, pp. 665-672.

Doc. Ing. Ivan Fořt, DrSc.

Ing. Tomáš Jirout

Prof. Ing. František Rieger, DrSc.,

Dept. of Process Engineering

phone: +4202 24352713

fax: +420224310292

e-mail: fort@fsid.cvut.cz

Czech Technical University in Prague

Faculty of Mechanical Engineering

Technická 4, 16607 Praha 6, Czech Republic

Ing. Ralf Allner

Prof. Dr. Ing. Reinhard Sperling

e-mail: reinhard.sperling@lbv.hs.anhalt.de

Dept. of Chemical Engineering

Anhalt University of Appl. Sciences

Hochschule Anhalt (FH)

Koethen, Germany 